\title{
FORMAÇÃO DE PROFESSORES: AS NARRATIVAS DE GRADUANDOS DA LICENCIATURA EM MATEMÁTICA DO IFRN/MOSSORÓ
}

\author{
F. C. S. SOUZA ${ }^{1}$, A. M. B. N. TAVARES ${ }^{2}$ e A. S. G. NASCIMENTO \\ Instituto Federal do Rio Grande do Norte \\ E-mail: chagas.souza@ifrn.edu.br ${ }^{1}$ e andrezza.tavares@ifrn.edu.br ${ }^{2}$
}

Artigo submetido em maio/2012 e aceito em maio/2012

\section{RESUMO}

Nas últimas décadas observamos um grande avanço na quantidade de pesquisas no campo das autobiografias e das histórias de vida. Este artigo trata de uma experiência que estamos desenvolvendo numa pesquisa de iniciação científica no curso de Licenciatura em Matemática do Instituto Federal de Educação, Ciência e Tecnologia do Rio Grande do Norte, Campus Mossoró. Buscamos conhecer as representações de futuros professores de Matemática, investigando sobre as suas trajetórias vida, as concepções sobre a profissão professor e as projeções quanto ao futuro profissional. A metodologia consta de narrativas autobiográficas escritas e orais de alunos do 5 o período de Matemática. Como primeiros resultados, podemos destacar que as narrativas nos mostram um conjunto de concepções sobre a profissão docente pautadas no discurso da desvalorização e da baixa-estima com relação ao ser professor. Apesar disso, muitos dos graduandos relatam a importância do curso para as suas vidas e dizem querer avançar nessa área, deixando evidente o fato de que somos educados continuamente a partir das nossas experiências cotidianas.

PALAVRAS-CHAVE: Narrativa; formação de professores; profissionalização.

\section{TEACHER TRAINING: THE NARRATIVES OF THE UNDERGRADUATES DEGREE IN MATH OF IFRN/MOSSORÓ}

\begin{abstract}
In recent decades seen a major advance in the amount of research in the field of autobiographies and life stories. This article is an experience that we are developing a scientific initiation in the Bachelor's Degree in Mathematics at the Federal Institute of Education, Science and Technology of Rio Grande do Norte, Campus Mossoró. We tried to know the representations of prospective teachers of mathematics, investigating on their life trajectories, the conception of the teacher profession and projections about the future professional. The methodology
\end{abstract}

consists of written and oral autobiographical narratives of students in 5th period math. As first results, we note that the stories show us a set of ideas about the teaching profession guided by the discourse of devaluation and low self-esteem in relation to being a teacher. Nevertheless, many of the students reported the importance of the course for their lives and say they want to advance in this area, making it clear the fact that we are continually educated from our everyday experiences.

KEY-WORDS: Narrative; teacher training; professionalization. 


\section{FORMAÇÃO DE PROFESSORES: AS NARRATIVAS DE GRADUANDOS DA LICENCIATURA EM MATEMÁTICA DO IFRN/MOSSORÓ}

\section{INTRODUÇÃO}

Este texto tem como objetivo relatar a trajetória do projeto de pesquisa Narrativas Autobiográficas na Formação Docente: uma experiência no curso de Licenciatura em Matemática do IFRN/Mossoró. Situado nos campos da narrativa, autobiografia e histórias de vida, o projeto vem sendo desenvolvido na modalidade de Iniciação Científica, no Campus Mossoró, do Instituto Federal de Educação, Ciência e Tecnologia do Rio Grande do Norte, com a turma de 5o período de Matemática.

As discussões acadêmicas sobre as narrativas autobiográficas têm mostrado a importância delas para o processo de formação docente, seja inicial ou continuada. Podemos destacar os estudos realizados por Josso (2010), Nóvoa (2007), Souza (2008), além de outros intelectuais brasileiros e estrangeiros.

Essa pesquisa é de caráter qualitativo e investigativo. Buscamos através das narrativas, escritas e orais, discutir as representações de futuros professores de Matemática quanto à profissão docente, às suas trajetórias vida, às projeções quanto ao futuro e às diversas escolhas que fizeram ao longo das suas vidas. Ou seja, julgamos pertinente conhecer outras facetas dos sujeitos que fazem o curso de Licenciatura Plena em Matemática, no IFRN/Mossoró, pois consideramos que tais particularidades - por serem da ordem da experiência humana e por estarem no âmbito de suas existências - não se deixam mostrar pelos números e gráficos estatísticos. Oportunizamos aos licenciandos em Matemática do IFRN/Mossoró uma discussão sobre a sua vida acadêmica.

A pesquisa vem se desenvolvendo desde abril de 2011. As primeiras narrativas deram-se depois que os alunos foram informados sobre os pressupostos da pesquisa e os seus objetivos. Os licenciandos em Matemática foram convidados a escrever sobre as seguintes questões: Que experiências influenciaram na sua escolha pelo curso de Licenciatura em Matemática, no IFRN? O que pensa sobre a profissão professor?

Nos parágrafos a seguir, trataremos de trechos dessas narrativas. É importante salientar que preferimos preservar a identidade dos alunos, substituindo os seus verdadeiros nomes por outros.

\section{A ESCRITA DE SI COMO ESTRATÉGIA DE FORMAÇÃO, A OBSERVAÇÃO E AS ENTREVISTAS NARRATIVAS}

O sentido que damos à nossa carreira é compreendido através das histórias de nossas vidas como pessoa e professores/as. Nóvoa (2007) afirma que a análise da formação não se pode fazer sem uma referência explícita ao modo como o adulto viveu situações concretas de seu próprio percurso educativo.

Sendo assim far-se-á o uso da escrita narrativa no intuito de recortar e delimitar as compreensões dos pesquisandos inseridos no processo de formação continuada a respeito de seu 
próprio percurso formativo mais especificamente dos saberes e competências referentes à postura de um professor investigador.

A escrita narrativa tem efeito formador por si só porque coloca o ator num campo reflexivo de tomada de consciência sobre sua existência, sentidos e conhecimentos que foram adquiridos ao longo da vida e, sendo assim, vislumbra possibilidades formativas construídas a partir das experiências vividas. Josso (2010) nos alerta de que a escrita narrativa funciona num primeiro plano na perspectiva das competências verbais e intelectuais, porque faz o sujeito entrar em contato com suas lembranças e evocar as "recordações-referências" que esteja implicado com o tema conhecimento de si e formação; fazendo com que este revele o que o sujeito aprendeu nas experiências que vivenciou nas suas vidas.

Em se tratando das entrevistas narrativas, Jovchelovith e Bauer (2002) salientam que a narração substitui o esquema pergunta-resposta. Assim, o informante estará usando sua própria linguagem espontânea na narração dos acontecimentos.

A metodologia da entrevista narrativa compreende cinco fases e regras singulares para a efetivação da mesma no processo da pesquisa narrativa, são elas: no primeiro momento, tem-se o período de preparação (exploração do campo e formulação de questões); num segundo período, tem-se a iniciação que consiste na formulação do tópico inicial para a narração; num terceiro período, vislumbra-se a fase das perguntas ou do questionamento, e por fim, tem-se a fase ou fala conclusiva da entrevista ao informante.

Após permear os passos da escrita e pesquisa narrativas além da observação empírica, tem-se o momento da análise dos dados extraídos e para tal análise. Para tanto, a análise realizar-se-á de forma temática após o momento das transcrições, principalmente, por propiciar um procedimento gradual de redução do texto qualitativo, desmembrando-o de forma sistemática, podendo apontar dados qualitativos e quantitativos, sem necessariamente perder a essência do texto escrito ou oral do informante.

\section{OS RELATOS DOS GRADUANDOS}

Escrever e refletir sobre si é tarefa sugerida há vários anos por estudiosos da formação de educadores como uma experiência que pode se configurar como transformadora da prática pedagógica. $\mathrm{O}$ grande contributo do método da escrita autobiográfica pode ser analisado por Demartini (2008, p. 46), "o ato de escrever, mesmo que quase mecanicamente, implica geralmente em pensar sobre o que se escreve". Na compreensão dos pesquisadores nessa área, essa reflexão sobre si mesmo possibilita a transformação do sujeito que escreve ao passo que este desconstrói a sua vida, para reconstruí-la, através da atribuição de novos sentidos.

$\mathrm{Na}$ nossa pesquisa podemos destacar a centralidade dos alunos assumindo nas narrativas papeis de autores e atores de suas próprias histórias. Narrar os traços pessoais a partir das experiências vividas tem possibilitado aos graduandos inscrever-se num espaço oportunista para o processo de sua formação profissional. A partir do momento em que começaram a refletir sobre si, eles transpuseram para as suas escritas, reflexões e sentimentos acerca de acontecimentos marcantes nas suas histórias de vida num tempo e espaço não necessariamente linear. Podemos perceber esse fato no relato de Sofia, que fala de lugares para onde foi levada, devido às circunstâncias econômicas da sua família:

Meus pais deram-me uma formação muito rigorosa e a meus irmãos também. Nasci em Areia Branca/RN, em 1965, e aos três anos nos mudamos para Brasília 
(minha família era composta por meu pai, minha mãe e mais três irmãos). Uma época muito difícil. Fomos morar em umas favelas que havia ao redor da construção da cidade. Meus pais sempre diziam que, por eu ser a mais velha dos quatro filhos teria que dar o exemplo a meus irmãos e desde cedo cuidava deles. Uma exigência de meus genitores era que eu não podia fazer nada errado, então tinha que estudar mais que os outros para dar o exemplo. Aos 14 anos, mudamos para Paracatu - MG. Aos 17, voltamos para Brasília e aos 19, tivemos que voltar para Mossoró por motivos financeiros.

Os relatos evidenciam as identidades que se constroem continuamente a partir das trajetórias de vidas dos alunos entrevistados. Sofia, por exemplo, é uma professora da rede pública de Mossoró e já tem um curso de graduação. Está fazendo outro, segundo ela, devido à necessidade que tem de aprender mais, pois isso lhe abrir mais oportunidades. Percebemos nas suas palavras, uma preocupação muito grande em se apresentar como uma pessoa rigorosa, fruto das exigências ditadas pelos pais e das dificuldades que encontrou ao longo da vida. Certamente, tais obstáculos fizeram com que ela tenha se tornado muito exigente consigo própria e com as pessoas com quem convive, inclusive com os seus alunos.

Certos traços das escritas dos alunos demonstram as representações destes sobre a profissão docente, pois, geralmente, a escolha do curso deu-se após várias tentativas de vestibulares em outras áreas, como podemos ver nos relatos a seguir.

Conclui o Ensino Médio regular em 2003 e logo em seguida estava trabalhando. Não passei no primeiro vestibular, e em seguida cursei Administração. Logo no início não me identifiquei com o curso e fui me desmotivando. Logo depois entrei no IFRN. (Luciana)

O meu primeiro vestibular foi para Ciências Econômicas e não passei. Depois fiz para Ciência e Tecnologia, também não passei. Tentei fazer o técnico no CEFET e não passei. Passou um tempo e comecei a trabalhar. Depois de algum tempo que trabalhava na loja, o meu irmão chegou dizendo tinha feito a minha inscrição no vestibular de Matemática no IFRN. Não passei, fiquei na suplência e muito triste também. Os dias foram passando e nada de me chamar. Um dia, cheguei do trabalho e fui jantar, a minha vizinha veio me chamar dizendo que era um telefonema para mim. Sai para atender. Era do IFRN dizendo que eu tinha passado. Fiquei tão feliz que comecei a chorar. (Paula)

Os textos de Luciana e Paula demonstram a persistência em realizar o sonho de fazer um curso superior, mas também as decepções que os vestibulares lhes trouxeram. A não identificação de Luciana com um curso que iniciou é bem próprio de uma jovem que ainda está à procura de uma identidade profissional. As tentativas frustradas de Paula em ter um curso superior ou técnico, o que lhe possibilitaria um futuro mais promissor que o trabalho como comerciária, faz com que ela se desestimule e pensasse em desistir. O papel do irmão, ao acreditar na sua aprovação no IFRN, é fator fundamental para que se eleve sua autoestima e volte a projetar um crescimento profissional, chorando de alegria ao saber que, finalmente, tinha conseguido ingressar em um curso de formação superior.

No entanto, mesmo que, para alguns, o curso atual não seja o que sonhou, os educandos falam da importância dele para as suas vidas e dizem querer avançar nessa área. Ser professor, 
especificamente da disciplina de Matemática, não fazia parte do plano profissional da grande maioria dos alunos, mas, no relato de Ana, a experiência que está passando na profissão está lhe fazendo rever a possibilidade:

\begin{abstract}
Licenciatura era a última alternativa profissional para mim. Como todo adolescente que esta concluindo o ensino médio eu sonhava com a independência financeira, uma carreira gloriosa (...). Prestei vestibular para turismo, área que estava em destaque na mídia e expandia rapidamente. Passei! Foi aquela alegria. No terceiro período já fui desanimando, vi que não daria pra mim, mas insisti e fui ate o 50 período, até que não deu mais. Antes de desistir por definitivo, consegui uma bolsa para dar aulas numa escola publica, onde lecionava Matemática (a disciplina que mais gostava nos tempos de escola), geografia e ciências. Era um desafio e tanto. Fui com a cara e a coragem. E o pior, eu comecei a gostar de dar aulas, gostava do ambiente, era como se eu realmente fosse uma professora, afinal, de fato eu era. Então um ano e meio após abandonar turismo, resolvi prestar vestibular novamente, agora sim, para Matemática, mas no fundo não estava entusiasmada. Mas tive o apoio de alguns familiares e amigos. (...) Gosto do que faço e espero que Deus me dê sabedoria e coragem para poder contribuir com o melhor que há em mim. Por uma escola melhor, uma comunidade melhor, uma cidade com cidadãos melhores, em fim um mundo melhor.
\end{abstract}

Ana, da mesma forma que as colegas, não projetava ser professora. A docência era, para ela, a "última alternativa", pois desejava ter uma "carreira gloriosa", ou seja, uma profissão que Ihe desse status. Pode-se afirmar que, inicialmente, a sua percepção quanto à profissão docente é marcada pelo preconceito disseminado pela sociedade e pela mídia. Aliás, foi a mídia que a levou a fazer um curso de turismo esperando deste um grande destaque profissional, mas que também não gostou, desistiu e resolveu procurar outras alternativas. Entretanto, depois de passar pela experiência de ser professora, refez o seu discurso e a concepção do ser docente. Hoje, considera que, por meio dessa profissão, poderá contribuir para uma sociedade mais justa. As considerações de Ana evidenciam o quanto as nossas representações e as nossas identidades são flexíveis e mutáveis de acordo com as experiências que vivenciamos.

Se a maior parte dos alunos disse que a escolha do curso não se deu pela importância dada a ele ou à profissão docente - e muitos já pensaram até mesmo em não continuar - outros dão valor ao curso e destacam o interesse em seguir em frente.

Na minha casa, a última coisa que a minha mãe queria é ter um filho professor $e$ desde sempre eu quis ser professora. Justamente pela questão financeira, ela dizia que professor não ganhava dinheiro e que professor não é valorizado. Para ela, o que importava era ter um status, porque professor não tem status. Das classes, professor é a menos valorizada, mas eu sempre quis ser professora, sempre gostei do contato, da troca de conhecimento que existe. Quando a gente é professor, a gente é um eterno aluno. A gente aprende todo dia com o aluno. (Sofia)

Eu não tinha uma expectativa de ser professora. Mais hoje, depois que entrei no curso, com o passar do tempo, eu tenho outra visão de tudo que esta acontecendo. Nas nossas discussões, ao ver a dificuldade e também a realidade, que não só são coisas ruins, que também tem o lado positivo de ser professor, de você esta dentro de uma sala de aula, de você contribuir para que aquele aluno não seja só detentor de conhecimento, mais sim, que ele se torne um cidadão, 
que você possa contribuir para isso também. A cada dia que passa, a cada exemplo, cada vez que a gente vê e discute, abre e desperta em mim mais a vontade de continuar, de tentar ser o melhor, de fazer o melhor. (Luciana)

Os comentários das duas alunas vão ao encontro dos discursos anteriores. Tratam de uma reprodução e, depois, de um questionamento das noções que a sociedade divulga sobre o ser professor. Os conceitos são revistos e os planos para o futuro são refeitos. Numa perspectiva freiriana, o ser professor, para as licenciandas em Matemática, não corresponde apenas à transmissão de conhecimentos, mas também na aprendizagem junto com aluno. Corroboram a perspectiva política da educação, ou seja, faz desta o meio para a transformação social e a conquista da cidadania, ideias tão caras a Paulo Freire em Pedagogia da autonomia (2008) e no manual de Didática de Libâneo (1994).

Esses depoimentos constatam a presença de aspectos negativos relacionados à percepção social da profissão professor e que se mostraram relevantes para a escolha da carreira. Os obstáculos vivenciados pelos professores, as constantes greves e outras mobilizações, os baixos salários, as extenuantes jornadas de trabalho, além de outros fatores, explicam a desmotivação dos graduandos pela docência. Numa sociedade de consumo como a nossa, ter dinheiro é fundamental para ser bem visto. Ter é mais importante do que ser.

Alguns entrevistados consideram a conquista de um diploma como uma oportunidade para a melhoria de vida, principalmente se esse sujeito vem de um grupo social de baixo poder aquisitivo. Mesmo que seja numa área que não pretende seguir carreira, muitos sonham em possuir um diploma, pois ele lhe dará uma melhor projeção perante uma sociedade que supervaloriza a educação formal. É o que podemos perceber na fala de André.

Não tenho a perspectiva de ser professor, o que eu quero do curso é a realização de ser diplomado, de ser uma pessoa formada, até pela realização dos meus pais verem que o filho foi formado na universidade. (André)

Há quem veja a profissão docente com bons olhos, mesmo apresentando as dificuldades que ela enfrenta.

[o professor] não é valorizado, não é bem visto. As pessoas têm certo receio quando dizem que é professor, principalmente de Matemática. Ser professor é questão de dedicação, de empenho, é de você fechar os olhos e os ouvidos, porque só mostrar as desvantagens todo mundo pode mostrar, é ai onde você tem que encontrar as vantagens. (...) A gente precisa mostrar que não estamos acima de ninguém, mas merecemos ser valorizados, porque todas as profissões passam por nós e no entanto não podemos exercer todas as profissões. Um médico pode ser professor, mas um professor pode ser médico? Não pode. Eu estou neste curso de graduação porque eu gosto de ensinar. Gosto da sala de aula. (Sofia)

O discurso de Sofia demonstra a força e a persistência para enfrentar os desafios da profissão docente, que não são poucos. Ela faz questão de apresentar os pontos positivos em ser professora, mas também ressalta o fato de que a profissão docente é um território invadido por outros profissionais. 
Durante a pesquisa, buscamos compreender as relações estabelecidas entre as trajetórias de vida, a docência e as percepções que os licenciandos em Matemática têm dessa profissão. Conforme, Souza (2008):

Trabalhar com narrativa escrita como perspectiva de formação possibilita ao sujeito aprender pela experiência, através de recordações-referências circunscritas no percurso da vida e permite entrar em contato com sentimentos, lembranças e subjetividades marcadas nas aprendizagens experienciais. $O$ mergulho interior possibilita ao sujeito construir sentido para a sua narrativa, através das associações livres do processo de evocação, num plano psicossomático, com base em experiências e aprendizagens construídas ao longo da vida. (p. 93)

A importância dada à narrativa por Souza, é reforçada por outros estudiosos da área, como Josso (2010), Nóvoa (2007), Cunha (1997), Demartini (2008), Fonseca (2009), dentre outros. Esses estudiosos partem da ideia muito em voga na atualidade de que a formação humana e profissional se dá continuamente nas nossas práticas cotidianas. No momento em que falamos de nós, das nossas experiências, das nossas escolhas, estamos refletindo sobre as mesmas e, consequentemente, estamos crescendo pessoal e profissionalmente.

As afirmações de Nóvoa (2007) de que "a maneira como cada um de nós ensina está diretamente dependente daquilo que somos como pessoa quando exercemos o ensino. (...) É impossível separar o eu profissional do eu pessoal." (p. 17. Grifo do autor) e de Fonseca (2009, p. 138), de que "o professor é uma pessoa, o aluno é uma pessoa", expressam muito bem a impossibilidade de separarmos o profissional do seu lado social e cultural.

Essa abordagem nos remete também às discussões sobre os saberes docentes tecidas por Tardif (2011). Para esse autor, trata-se daqueles saberes adquiridos ao longo da vida e da experiência profissional.

O saber não é uma coisa que flutua no espaço: o saber dos professores é o saber deles e está relacionado com a sua experiência de vida e com a sua história profissional, com as suas relações com os alunos em sala de aula e com os outros atores escolares na escola, etc. Por isso, é necessário estudá-lo relacionando-o com esses elementos constitutivos do trabalho docente. (TARDIF, 2011, p. 11. Grifo do autor)

Contar-se pode ser um processo profundamente emancipatório em que o sujeito aprende a produzir sua própria formação, autodeterminando a sua trajetória. Assim, se o sujeito é um futuro profissional da educação, o método das histórias de vida pode ser explorado com fins pedagógicos em sala de aula como observa Fonseca (2009) e Catani (2005).

Enfim, a produção autobiográfica realizada no tempo e no espaço formativo dá aos licenciandos em Matemática do IFRN uma oportunidade de repensar sobre suas escolhas, revisar suas concepções e suas representações sobre o ser professor e a figura deste profissional em sua vida. Possibilita também problematizar as suas relações sociais, suas atividades práticas e a necessidade humana de querer "ser mais", humanizar-se, como diz Paulo Freire.

\section{REFERÊNCIAS}


CATANI, Denice B. A didática como iniciação: uma alternativa no processo de formação de professores. In: CASTRO, Amelia D.; CARVALHO, Anna Maria P. (Orgs.) Ensinar a ensinar: didática para a Escola Fundamental e Média. São Paulo: Thomson, 2005, p. 53-72.

CUNHA, Maria Isabel da. CONTA-ME AGORA! as narrativas como alternativas pedagógicas na pesquisa e no ensino. Revista da Faculdade de Educação. v. 23 n. 1-2 São Paulo Jan./Dez. 1997

DEMARTINI, Zeila de B. F. Das histórias de vida às histórias de formação. In: SOUZA, Elizeu C. de.; MIGNOT, Ana C. V. (Orgs.) História de vida e formação de professores. Rio de Janeiro: Quartet: FAPERJ, 2008. p. 39-64.

FONSECA, Selva G. Aprender a contar, a ouvir, a viver: as narrativas como processo de formação. In: VEIGA, Ilma Passos. A. (Org.). Técnicas de ensino: novos tempos, novas configurações. 2 ed. Campinas-SP: Papirus, 2009. p. 137-162.

FREIRE, Paulo. Pedagogia da autonomia: saberes necessários à prática educativa. 37 ed. São Paulo: Paz e Terra, 2008.

JOSSO, Marie C. Da formação do sujeito... Ao sujeito da formação. In: NÓVOA, António; FINGER, Matthias. (Orgs.) $O$ método (auto)biográfico e a formação. Natal-RN: EDUFRN; São Paulo: Paulus, 2010. p. 59-79.

JOVCHELOVITCH, Sandra.; BAUER, Martin W.. Entrevista narrativa. In: BAUER, M. W. GASKELL, G. Pesquisa qualitativa com texto, imagem e som. Petrópolis: Vozes, 2002.

NÓVOA, António. Os professores e as histórias de suas vidas. In: (Org.) Vidas de professores. 2 ed. Porto: Porto Editora, 2007. p. 11-30.

SOUZA, Elizeu C. Histórias de Vida e Formação de Professores. In: (Org.) Histórias de vida, escritas de si e abordagem experiencial. Rio de Janeiro: Quartet: FAPERJ, 2008. p. 90-95. 